\title{
Core Biopsy of Breast
}

National Cancer Institute

\section{Source}

National Cancer Institute. Core Biopsy of Breast. NCI Thesaurus. Code C137851.

The removal of breast tissue using a needle with a relatively large diameter, for

microscopic examination. 